\title{
Magnetic dipolarization with substorm expansion onset
}

\author{
K. Liou, C.-I. Meng, A. T. Y. Lui, P. T. Newell, and S. Wing \\ Applied Physics Laboratory, Johns Hopkins University, Laurel, Maryland, USA
}

Received 18 June 2001; revised 23 October 2001; accepted 14 November 2001; published 24 July 2002.

[1] We compare the timing and spatial extent of dipolarization with auroral breakup by using magnetic field data (1-min time resolution) from GOES 8 and GOES 9 and global auroral images (37-s frame rate) from the Polar ultraviolet imager. We survey the entire year of 1997 data and obtain 32 unambiguous dipolarization events that had ionospheric footprints within 2 hours in magnetic local time (MLT) from their associated auroral breakups. It is found that the auroral breakup preceded the arrival of dipolarization at GOES by an average of $1.7 \pm 2.7 \mathrm{~min}$. ( $1.0 \pm 2.1 \mathrm{~min}$ for events \pm 1 hour from the auroral breakup). The delay of geosynchronous dipolarization represents a propagation time, as the substorms rarely initiated at the GOES location. Propagation velocities derived from the propagation time are $\sim 60 \mathrm{~km} \mathrm{~s}^{-1}$ eastward, $\sim 75 \mathrm{~km} \mathrm{~s}^{-1}$ westward, and $\sim 270 \mathrm{~km} \mathrm{~s}^{-1}$ earthward at geosynchronous orbit. We also show for the first time that auroral bulge and dipolarization region closely map; the bulge is the region of currents out of the ionosphere. The eastern edge of the dipolarization region, where field-aligned currents are flowing into the ionosphere, is, based on the T89 magnetic field model, located at $\sim 0.5$ hour in MLT eastward of the eastern edge of the auroral bulge. Within the initiation site meridian the dipolarization onset was observed $\sim 1$ min prior to the auroral breakup at the GOES altitude. This time is associated with Alfvén transit time and therefore depends on the radial location of the onset. The azimuthal scale of the initiation site is found to be $\sim 0.5$ hour in MLT in the ionosphere or less than $\sim 1$ Earth's radius at $6.6 R_{E}$. These results support current diversion into the ionosphere as a critical part of substorms. Finally, a simple timing analysis of specific substorm onset time features suggests that near-Earth reconnection cannot occur before current disruption and therefore cannot be the cause of substorm. INDEX TERMS: 2788 Magnetospheric Physics: Storms and substorms; 2704 Magnetospheric Physics: Auroral phenomena (2407); 2730 Magnetospheric Physics: Magnetosphere-inner; KEYWORDS: substorm onset, magnetic dipolarization, onset timing, auroral breakups

\section{Introduction}

[2] Enhanced magnetotail stretching occurring during the "growth phase" of a substorm has become, in general, a consensus in the substorm community. Prior to the onset of a substorm, the cross-tail current sheet intensifies, and the magnetic field at geosynchronous orbit becomes very stressed and tail-like [Fairfield and Ness, 1970; Sauvaud and Winckler, 1980; Kokubun and McPherron, 1981; Nagai, 1982; Kaufmann, 1987; Lopez et al., 1998]. Intensification of the sheet current is particularly pronounced in the near-Earth $\left(\leq 10 R_{E}\right)$ equatorial plasma sheet [Lui, 1991; Kennel, 1992]. The process of magnetic field stretching is found to cease abruptly at substorm onset, and the configuration of field line changes from a tail-like to a dipole-like orientation [Cumming et al., 1968; McPherron et al., 1973; Sauvaud and Winckler, 1980; Kokubun and McPherron, 1981].

Copyright 2002 by the American Geophysical Union. 0148-0227/02/2001JA000179\$09.00
[3] The later process is often referred to as "dipolarization" and is often interpreted as a diversion of the cross-tail current into the ionosphere forming a substorm current wedge (SCW) [Bonnevier and Rostoker, 1970; McPherron et al., 1973; Rostoker, 1974].

[4] Stretching and releasing of the Earth's magnetic field can be routinely monitored with satellites stationed at geosynchronous orbit as this process is associated with crosstail current enhancement and disruption in the near-Earth plasma sheet from 6 to $10 R_{E}$ [Lui, 1991; Kennel, 1992]. Characteristics of magnetic field configuration at geosynchronous orbit during substorm periods were established some 2 decades ago. Dipolarization starts in a longitudinally confined region and is followed immediately by an azimuthal expansion in either direction after onset [Kokubun and McPherron, 1981; Nagai, 1982]. Nagai [1982] found that variations in the eastward component of magnetic field occur simultaneously (with less than 2 min in difference) with magnetic substorm onset, determined by the start of magnetic positive bays at low-latitude stations. The time difference between the onset of a dipolarization and the start 
of a positive magnetic bay is local time dependent; it is smallest in the premidnight region and tends to increase with the increase of local time separation from midnight.

[5] Substorm onset timing has renewed its attention lately owing to the widely available data set from the coordinated International Solar Terrestrial Physics(ISTP) satellite and ground-based observations. Precise timing of onset signatures may shed light on the mechanism of onset. In a series of recent works [Liou et al., 1999, 2000a, 2000b, 2001a] we demonstrated that most of the substorm onset identifiers, including high-latitude magnetic bays, $\mathrm{Pi} 2$ magnetic pulsations, auroral kilometric radiations, and dispersionless energetic particle injections, are subject to propagation-related delay. We showed that the delays were mainly caused by measurements of these onset signatures not being local to the initiation region. Therefore auroral breakup is the best diagnostic of substorm onset when identified with global auroral imagers.

[6] Being one of the major signatures of magnetospheric substorm expansion phase onset, dipolarization can be used to time substorm onset. Recently, Frank et al. [2000] reported a fortuitous event of simultaneous dipolarization onset, observed by Geotail at $\sim 14 R_{E}$, and auroral breakup, observed by the Polar visible imaging system (VIS). Since cross-tail current disruption typically takes place just a few Earth's radii outside the geosynchronous orbit [Lui, 1991; Kennel, 1992], delays in dipolarization onset time at geosynchronous orbit with respect to auroral breakup are therefore expected. Relative timing between dipolarization onset at geosynchronous orbit and auroral breakup has not been established and deserves an investigation.

[7] Magnetic field signatures seen at geosynchronous orbit are expected to be closely related to substorm-associated auroral expansion. According to the substorm current wedge model [Atkinson, 1967; McPherron et al., 1973], dipolarization is associated with disruption and diversion of part of the magnetospheric cross-tail current into the auroral ionosphere, where it flows across the substorm central meridian in the westward electrojet. As the auroral bulge expands during the substorm expansion phase, the region covered by the electrojet current expands as well. Similarly, the disrupted current, which is initially confined to a small region, later expands longitudinally and radially during substorm expansion phase [Lopez et al., 1990]. If dipolarization is confined to the region of current disruption, it should increase in harmony with the expansion of aurora during the substorm expansion phase.

[8] Some of the predications of the substorm current wedge model have been more or less confirmed by a number of observations. Pellinen et al. [1984] reported a few cases in which the impulsive horizontal component of electric field fluctuations and the westward traveling surge associated with substorm auroral bulge were observed at the same time, respectively, by GOES 2 geosynchronous satellite and its conjugate ground-based all-sky auroral images. They interpreted the observed electric field as a result of an inductive effect of a downward field-aligned current. More direct evidence was reported later by Gelpi et al. [1987]. In two of the three Defense Meteorological Satellite Program (DMSP) images of substorm auroral surge studied, Gelpi et al. [1987] found that magnetic field at geosynchronous orbit was tail-like when the GOES magnetic footprint was out- side and to the west of the surge, whereas magnetic field was dipole-like when the GOES magnetic footprint was inside the surge. It is important to note that the interpretation of these results was somewhat compromised by the limitations of these measurement techniques, and direct observational evidence that can unambiguously relate dipolarization with substorm auroral bulge is yet to be found. In the present paper we will provide a detail dipolarizationauroral bulge relationship by analyzing global auroral images acquired from the ultraviolet imager (UVI) on board the Polar satellite.

[9] The outline of the remaining part of the paper is as follows. In section 2 we first describe the typical magnetic field configuration at geosynchronous orbit before and after substorm onset by using superposed epoch analysis. The time difference between dipolarization onset and auroral breakup is examined. The possible cause of the time difference will also be investigated. A detailed discussion of the results is given in section 3 , followed by conclusions in section 4 .

\section{Observations}

[10] The present investigation utilizes global auroral images acquired from the ultraviolet imager [Torr et al., 1995] on board the Polar spacecraft to identify substorm events and determine their onset times. The Polar UVI is capable of providing continuous, full or partial coverage of the northern auroral oval at a temporal resolution of $\sim 37 \mathrm{~s}$. Fluxgate magnetometer data of 1-min time resolution from the National Oceanic and Atmospheric Administration (NOAA) synchronous $\left(r \sim 6.6 R_{E}\right)$ weather satellites GOES $8\left(\sim 75^{\circ} \mathrm{W}\right)$ and GOES $9\left(\sim 135^{\circ} \mathrm{W}\right)$ are used for examining magnetic field dipolarization.

[11] We first examine the Polar UVI images to identify substorm events based on the classical auroral substorm scheme depicted by Akasofu [1964]. A detailed procedure of determining substorm onset is given by Liou et al. [2001b]. A total of 523 substorms with clear onset and expansion features are identified in the entire year of 1997. We then search the GOES database for dipolarization signatures during the periods of the 523 substorm events. A set of procedures are adopted here for selecting dipolarization events. The GOES magnetic field data are first converted to the $\mathrm{VDH}$ coordinate system. In this coordinate system, $H$ is antiparallel to the dipole axis, $V$ points radially outward and is parallel to the magnetic equator, and $D$ completes the right-hand orthogonal system and is positive eastward. The magnetic elevation angle, defined as $\tan ^{-1}\left(-B_{H} / B_{V}\right)$, is then calculated. We examine the degree of magnetic inclination to identify dipolarization events. The onset of dipolarization is defined as the start of the field line reconfiguration from a stretched to a more dipole-like orientation. A decrease of $\sim 10^{\circ}$ in the elevation angle within $\sim 10 \mathrm{~min}$ is required to be considered as dipolarization. This condition generally eliminates small substorm events. Lastly, we required dipolarization to be observed within 2 hours in magnetic local time (MLT) of the location of auroral breakup. This requirement is based on the fact that a dispersionless energetic particle injection can only be seen \pm 2 hours of MLT from an auroral breakup [Liou, 2001a]. Under these procedures/criteria a total of 32 unambiguous dipolarization onsets seen either at GOES 8 or 


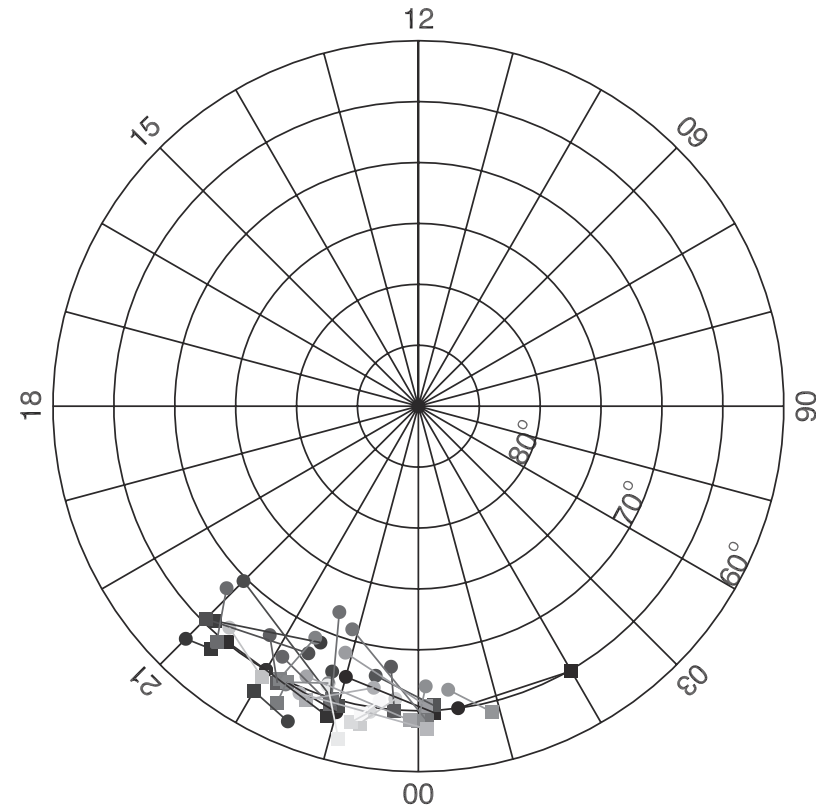

Figure 1. Distribution of 32 auroral breakup locations (solid circles) and ionospheric footprints of GOES satellites (solid squares). Events are connected by straight lines. The average (median) breakup location is 2241 (2248) MLT and $66.7^{\circ}\left(66.6^{\circ}\right)$ MLAT, and the average (median) ionospheric footprint of GOES is 2258 (2254) MLT and 64.3 $\left(64.5^{\circ}\right)$ MLAT.

GOES 9 are selected. The average (median) breakup location is 2241 (2248) MLT and $66.7^{\circ}\left(66.6^{\circ}\right)$ MLAT, and the average (median) ionospheric footprint of GOES is 2258 (2254) MLT and $64.3^{\circ}$ (64.5 ${ }^{\circ}$ ) MLAT (see Figure 1).

[12] For each event the ionospheric footprints of the GOES 8 and GOES 9 satellites are calculated with the T89 magnetic field model [Tsyganenko, 1989]. The centroid of the auroral onset arcs (usually a bright spot in UVI) is also determined.

[13] Averaged magnetic field characteristics for the 32 substorm events are first studied using superposed epoch analysis technique, and the results are shown in Figure 2. The three components of magnetic field are plotted in Figures $2 a-2 c$. Prior to the auroral breakup (the zero epoch time), the radial $(V)$ component of the magnetic field progressively increased, while the north $(H)$ component of the magnetic field progressively decreased, indicating stretching of the magnetic field. This preonset magnetic field signature also appeared in the magnetic elevation angle in Figure $2 \mathrm{~d}$ as early as 1 hour prior to the auroral breakup. This process of field line stretching ceased $\sim 1-2$ min prior to the auroral onset and became dipolarized in $\sim 10-20 \mathrm{~min}$. After onset the magnetic field was overcompensating and lasted $\sim 1$ hour. Note that there is a small difference in determining the onset time of dipolarization from the $H$ component and $V$ component of magnetic field. To circumvent this ambiguity, we use elevation angles to determine the onset time. Polarity of field-aligned currents associated with dipolarization can be determined from the $D$ component of magnetic field. As expected, the fieldaligned currents were small at geosynchronous orbit before onset. Immediately after onset, a positive change in the $D$ component of magnetic field indicates the GOES satellites were located, on average, at magnetic fluxes of upward field-aligned currents. To study variations of magnetic field strength before and after the onset, magnetic field strength for each event is subtracted from its preonset hourly average and is superimposed over the 32 events to yield Figure 2e. It is clear that the magnitude of magnetic field did not change significantly before onset. After onset, however, the field strength increased by $\sim 10 \mathrm{nT}$ in $\sim 20$ min and reached its maximum. The maximal field strength occurred when the elevation angle reached its maximum. Note that the onset of the explosive magnetic field increase was not coincident with the auroral breakup. A $\sim 5-\mathrm{min}$ delay can be discerned.
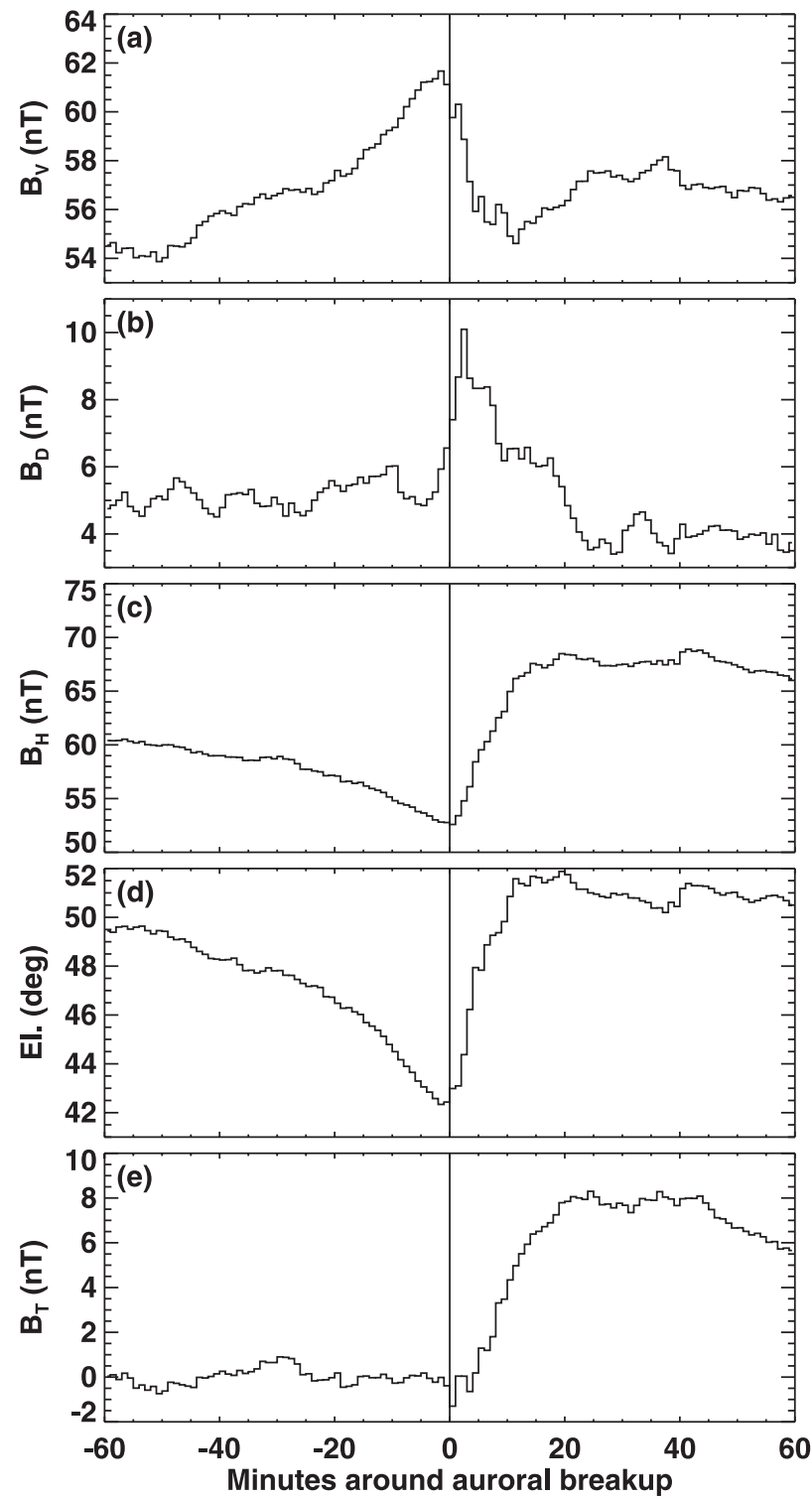

Figure 2. Superposed epoch analysis of the (a) $V$ component, (b) $D$ component, (c) $H$ component, (d) elevation angles, and (e) total magnitude changes of the GOES magnetic field from the 32 substorm events that occurred \pm 2 hours in MLT of the breakup. The zero epoch is the auroral breakup time and is marked by a vertical line in each row. 
[14] Time differences between the dipolarization onset and the auroral breakup for the 32 events are also calculated. The event histogram plotted against the onset time differences, $T d 0-T a 0$, where $T d 0$ is the time for the arrival of dipolarizations at GOES and $T a 0$ is the time of auroral breakups, is shown in Figure 3. The majority of events were clustered around bins from -1 to $2 \mathrm{~min}$ with a peak at the $0-1$ min bin. However, there were a few events scattering to the right, indicating further delays of the dipolarization seen at geosynchronous orbit. The average delay time is $1.7 \mathrm{~min}$ with a large standard deviation of $2.7 \mathrm{~min}$. The delay time is slightly reduced to $1.0 \pm 2.1 \mathrm{~min}$ if events were limited to \pm 1 hour in MLT of the breakup (23 events in total in this category).

[15] Although the delay of the geosynchronous dipolarization onset relative to the auroral breakup is small on average, the actual delay can be as large as $9 \mathrm{~min}$. To understand the delay, we first examine in detail a substorm event that occurred on 17 July 1997. Figure 4 shows a sequence of nightside auroral images in the $\mathrm{N}_{2}$ LymanBirge-Hopfield (LBH) bands acquired from Polar UVI during a substorm period that commenced at 2100 MLT and $68^{\circ}$ MLAT at $\sim 0635$ UT. At the time of onset, GOES 9 was located at $\sim 2100$ MLT, the same local time but $\sim 2^{\circ}$ in magnetic latitude (MLAT) equatorward of the auroral breakup, while GOES 8 was located at $\sim 0130$ MLT, $\sim 4.5$ hours in MLT east of the auroral breakup. For this particular event, expansion of the auroral bulge was primarily eastward.

[16] Figure 5 shows the elevation angles and the $D$ component of the magnetic fields at GOES 8 and GOES 9 during the substorm interval from 0530 to 0730 UT. Although the two satellites were about the same distance from the midnight and both observed magnetic field stretching and dipolarization signatures, the time for the dipolarization arrival at the two satellite locations differs significantly. The dipolarization onset at GOES 9 occurred at 0635 UT, simultaneously with the auroral breakup. After onset the field at GOES 8 continued to become more taillike until the arrival of the dipolarization at 0648 UT, 13 min after the auroral breakup. Detailed examination of the sequence of auroral images in Figure 4 indicates that the delay of the dipolarization onset at GOES 8 is almost consistent with the time when the substorm auroral bulge reached the ionospheric footprint of the GOES 8 satellite. There was $\sim 0.5$ hour in MLT offset in the eastward edge of the auroral bulge and the GOES 8 satellite footprint at the dipolarization onset time at 0648 UT, with the auroral bulge being west of the dipolarization.

[17] The $D$ component of the magnetic field at GOES 8 had a negative change starting at the auroral breakup and reached a minimum $\left(\Delta B_{D} \sim 40 \mathrm{nT}\right)$ at the local dipolarization onset, indicating that a downward field-aligned current westward of GOES 8, presumably associated with the auroral breakup, was moving eastward toward GOES 8 . Variations of $B_{D}$ changed sign to positive from negative at $\sim 0648$ UT when the expanded auroral bulge almost reached the local time of GOES 8. At GOES 9, which was located at the same meridian as the auroral breakup, the $D$ component of the magnetic field showed a dipolar configuration: an increase in $B_{D}$ (an upward field-aligned current) started $\sim 8$ min before the auroral breakup, a sharp $B_{D}$ drop immediately after the breakup $\left(\Delta B_{D} \sim 6 \mathrm{nT}\right)$, and a slow recovery.

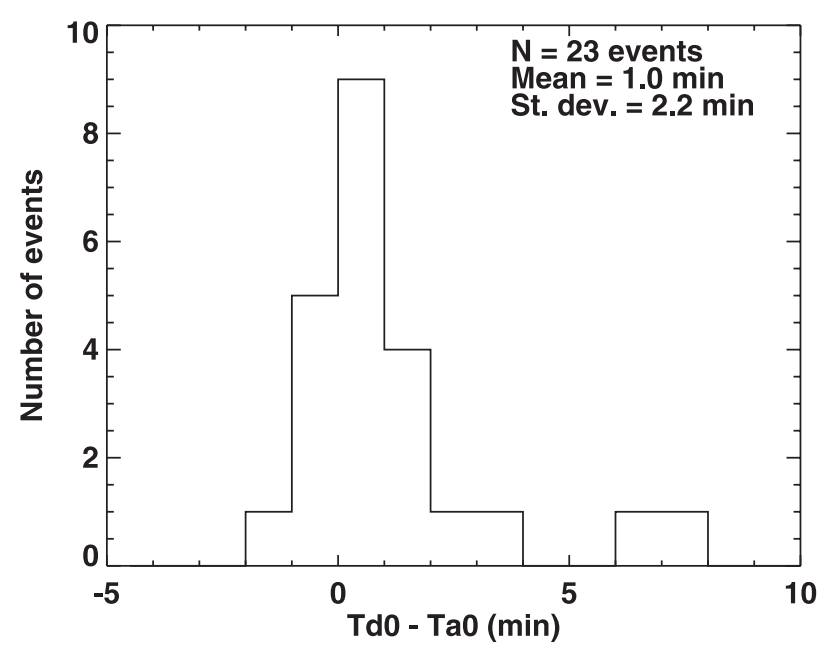

Figure 3. Distribution of magnetic field dipolarization onset time $(T d 0)$ at geosynchronous orbit relative to auroral breakup time $(\mathrm{Ta} 0)$.

Since GOES 9 was located at $\sim 2130$ MLT, the preonset $B_{D}$ increase is most likely associated with an enhanced neutral sheet current or earthward displacement of the neutral sheet current. After the auroral breakup a downward field-aligned current associated with a substorm current wedge prevailed at GOES 9 but slowly faded away as the auroral bulge expanded eastward.

[18] Another substorm event that describes the westward edge of dipolarization occurred on 6 September 1997. A sequence of Polar UVI auroral images of the nightside auroral oval in LBH bands from 0542 to 0518 UT are shown in Figure 6. In this event the auroral breakup took place at $2230 \mathrm{MLT}$ and $66^{\circ}$ MLAT at $\sim 0457$ UT. Note that a localized brightening took place at $\sim 0100$ MLT just eastward of GOES 8 a few minutes prior to the onset but faded thereafter. At the time of onset, GOES 8 was located at midnight, and GOES 9 was located at $\sim 2000$ MLT. For this particular event, expansion of the auroral bulge is more pronounced westward than eastward.

[19] Magnetic field behavior during the substorm period at GOES 8 and GOES 9 from 0400 to 0600 UT is given in Figure 7. According to the Polar UVI images, GOES 8 was located near midnight and just westward of the breakup meridian. A clear preonset signature of progressive magnetic field stretching that started at $\sim 0330$ UT (not shown) is observed prior to the onset. The $D$ component of the magnetic field indicates an impulsive positive change prior to the onset, indicating the existence of an upward (out of the ionosphere) field-aligned current at or eastward of GOES 8. This field-aligned current may be associated with the small brightening of aurora eastward of the GOES 8 meridian just prior to the onset. A small excursion in the elevation angle but quickly overtaken by the progressive trend of field stretching can also be seen in Figure 2a. Right before the onset the $D$ component of the magnetic field dropped sharply and resulted in a net negative change after the onset. The implied field-aligned current was downward (into the ionosphere) at or westward of the GOES 8 meridian. According to the auroral images, GOES 8 was located at $\sim 1$ hour in MLT eastward of the onset bulge. It is 

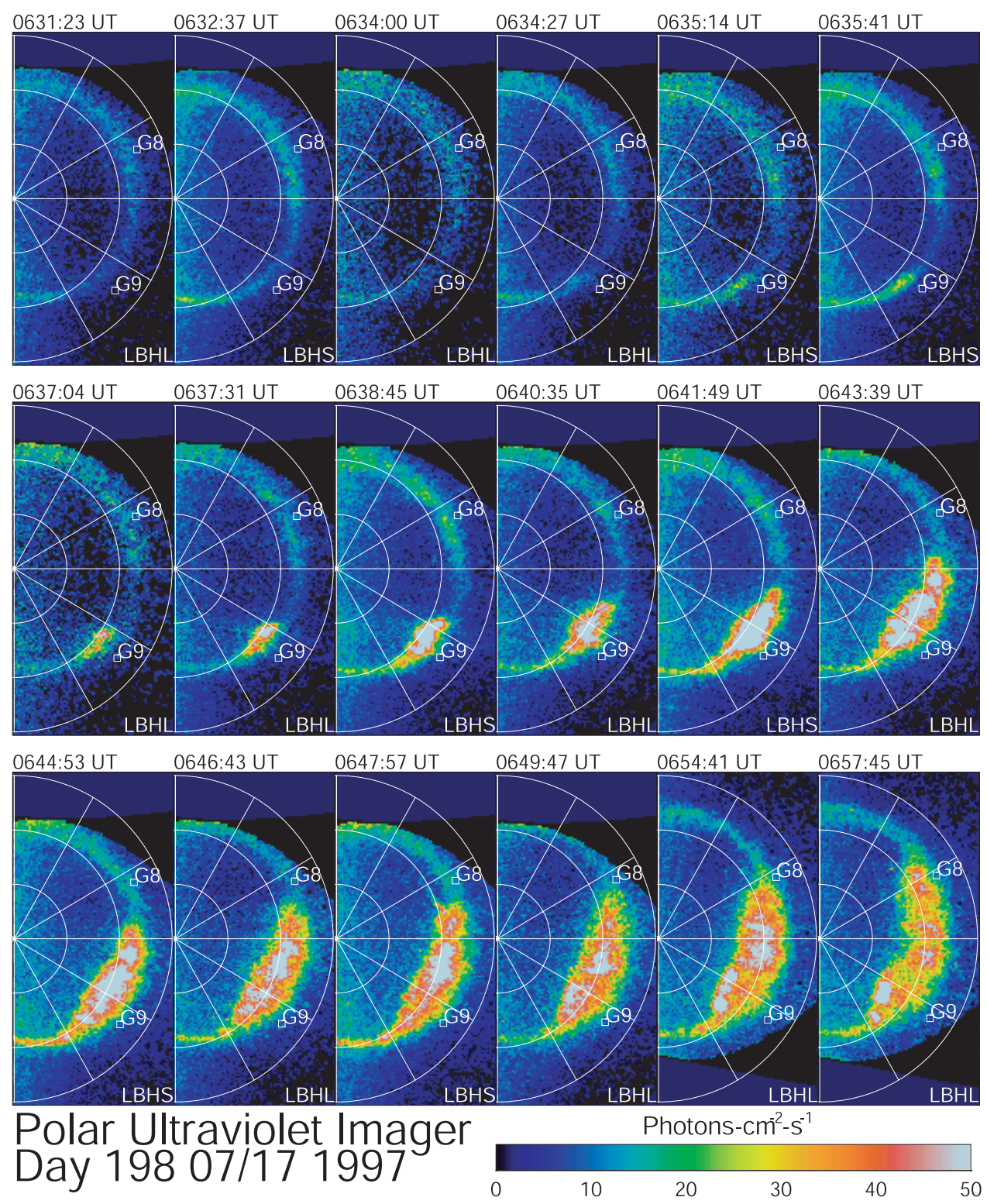

Figure 4. A sequence of nightside auroral images in the $\mathrm{N}_{2}$ Lyman-Birge-Hopfield (LBH) bands from Polar ultraviolet imager showing auroral breakup at $~ 0635: 41$ UT on 17 July 1997. The time tag indicates the center of each snapshot accumulated in $36 \mathrm{~s}$. The magnetic latitude $\left(10^{\circ}\right.$ increments $)$ and magnetic local time (2-hour increments; dusk at the bottom of each frame and midnight to the right of each frame) are in Altitude Adjusted Corrected Geomagnetic Coordinates (AACGM) [Baker and Wing, 1989].

expected that a large field-aligned current flows into the ionosphere from the eastern side of the intensified auroral region and that a large field-aligned current flows out of the region to form a substorm current wedge.

[20] Magnetic field signatures at GOES 9, which was located only a few Earth's radii eastward of the onset meridian, revealed a slower and smaller decrease in the elevation angles than those of GOES 8 before the breakup (see Figure 7c). A slow and small increase in the elevation angle appeared $\sim 10 \mathrm{~min}$ before the breakup. Interestingly, the elevation angle dropped at a much faster rate after the breakup until $\sim 0508 \mathrm{UT}$, when the auroral bulge expanded westward and reached the meridian of the GOES 9 ionospheric footprint. The $D$ component of magnetic field had a positive change starting $\sim 10$ min before the breakup and reached its maximum $\sim 10 \mathrm{~min}$ after the breakup. This implied that an upward field-aligned current was located eastward of the GOES 9 meridian during the onset period, in good agreement with the auroral images.

[21] These two events clearly demonstrated the temporal and spatial relationship between substorm auroral bulge in the ionosphere and dipolarization region in the magnetosphere. The longitudinal separation of the satellite from the substorm auroral surge and the speed of bulge expansion 


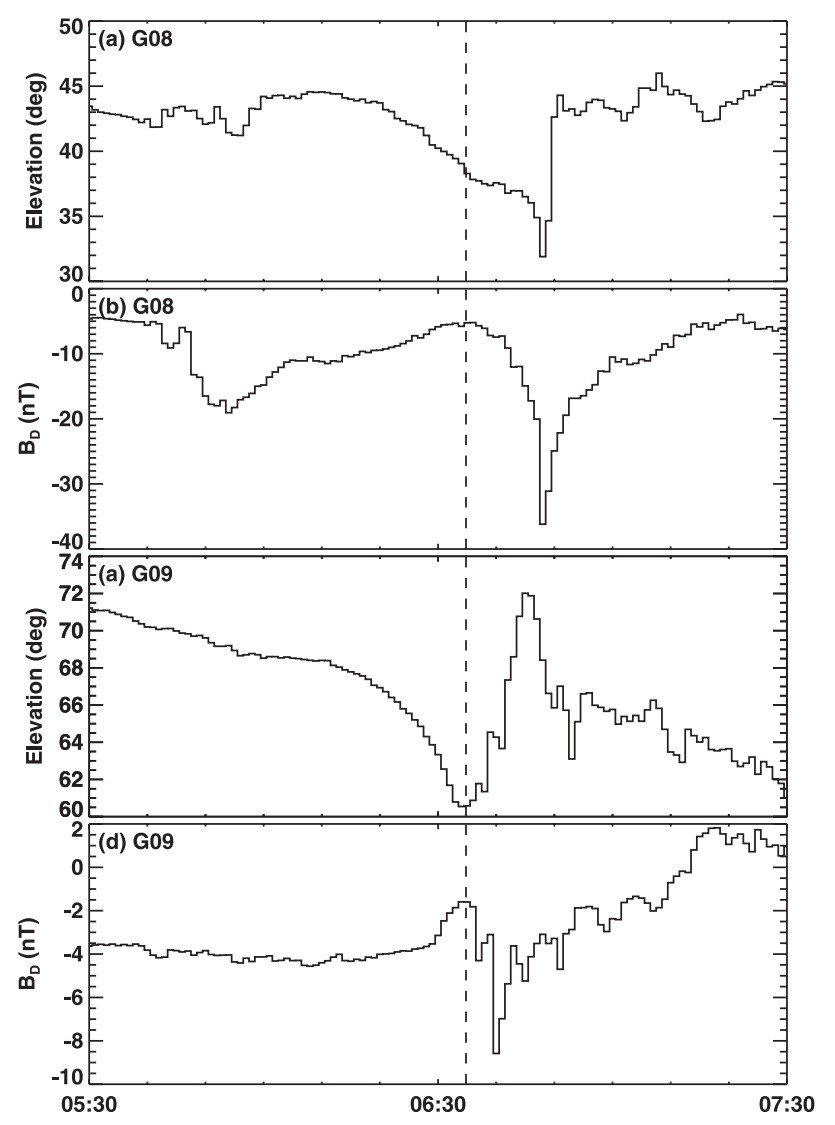

Figure 5. (a, c) The elevation angles and (b, d) $D$ component (east) of magnetic fields from GOES 8 and GOES 9, respectively, from 0530 to 0730 UT on 17 July 1997. The vertical dashed line marks the auroral onset time.

certainly play an important role in determining the dipolarization onset time. It is important to point out that in these two events both substorms were initiated just outside the geosynchronous orbit. The simultaneity of auroral breakup and dipolarization onset at GOES 9 for the first event and at GOES 8 for the second event indicates that the dipolarization may have occurred prior to the breakup because it takes finite time for moving magnetic flux to the GOES satellites from the onset regions.

[22] To further illustrate this spatial effect, we plot time differences between the two onset signatures as a function of the magnetic location time and latitude, with both local times and latitudes of dipolarization onsets being centered at the breakup location, in Figure 8. Note that both GOES 8 and GOES 9 observations of dipolarization for the 32 events are included in Figure 8, adding up to a total of 51 events. The time differences between the dipolarization onset and auroral breakup, $T d 0-T a 0$, are color-coded ranging from -2 to $20 \mathrm{~min}$. It is clearly indicated that the dipolarization onset observed at geosynchronous orbit often followed (positive values) the auroral breakup. Several results can be drawn from Figure 8. First of all, most of the surveyed auroral breakups were located poleward (negative values for MLAT around breakup) of the footprint of the GOES satellites or, equally speaking, most of the surveyed auroral breakups map to the magnetospheric equator outside the geosynchronous orbit. Second, there are more green dots (less delay) than red dots (more delay) near the center of auroral breakup, indicating the delay time of dipolarization onset increases with the increase of the local time separation from breakup. This also can be seen from the top panel of Figure 8 in which average delay time (over a 1-hour bin) is plotted as a function of MLT. Third, there are more green dots to the east than to the west of the auroral breakup, indicating that the center of dipolarization region is located on the east of the auroral breakup. The minimum time delay was found to occur at $\sim 0.5$ hour east of the auroral breakup. Fourth, at this local time, dipolarization onset was found to precede the auroral breakup by $\sim 1$ min. Finally, the delay time of dipolarization onset seen at GOES is also related to their radial expansion of substorm onset/current disruption region. Interestingly, the minimum delay time seems to occur when the footprints of the GOES satellites were $\sim 1^{\circ}$ poleward of the auroral breakup.

[23] The azimuthal expansion speed of the auroral bulge or, equivalently speaking, the azimuthal expansion speed of the dipolarization region can be estimated from the top panel of Figure 8. Linear regressions yield a westward speed of $\sim 4.9^{\circ} \mathrm{min}^{-1}$ and a eastward speed of $\sim 6.1^{\circ}$ $\min ^{-1}$. These values translate to $60 \mathrm{~km} \mathrm{~s}^{-1}$ westward and $75 \mathrm{~km} \mathrm{~s}^{-1}$ eastward at $6.6 R_{E}$. Similarly, the earthward expansion speed of the substorm onset/current disruption region is estimated from the right panel of Figure 8 to be $\sim 0.84^{\circ} \mathrm{min}^{-1}$. Converting this value to an actual speed in the magnetosphere is nontrivial because it requires a realistic magnetic field model. The empirical Tsyganenko T89 is an average geomagnetic field model parameterized by $K p$ [Tsyganenko, 1989] and therefore cannot simulate the very stretched, tail-like field line prior to substorm onset. To a reasonable approximation, $1^{\circ}$ in MLAT in the auroral oval latitude in the ionosphere corresponds to $3 R_{E}$, on average, in the near-Earth tail. Therefore the earthward speed is estimated to be in the range of $\sim 270 \mathrm{~km} \mathrm{~s}^{-1}$, which is in agreement with previous results [Russell, 1973; Ohtani, 1998]. The substorm initiation site can be estimated by using the average delay time of dipolarization at geosynchronous orbit. In order to eliminate azimuthal expansion effect, dipolarization events are limited to \pm 1 hour from the auroral breakup. Under this criterion the average delay time is $1.0 \mathrm{~min}$, and the upper limit of average radial distance for the initiation site is estimated to be $8.3 R_{E}$.

\section{Discussion}

[24] Dipolarization of magnetic field at geosynchronous altitude during substorm periods was investigated, with emphasis on its timing and longitudinal extent relative to auroral breakup. It has been shown that auroral breakup is the most consistent and reliable substorm onset identifier [Liou et al., 1999]. With a typical 37-s imaging rate from UVI, the uncertainty in timing the auroral breakup should be no more than $1 \mathrm{~min}$ on average. Combining with the 1min time resolution of magnetic field data from GOES 8 and GOES 9, an uncertainty of $1 \mathrm{~min}( \pm 30 \mathrm{~s})$ should be borne in mind when interpreting some case results.

[25] Superposed epoch analysis from 32 dipolarization onsets that occurred within 2 hours in MLT of the auroral breakup meridian indicates that continuous stretching of magnetic field is a typical preonset signature. This stretching 


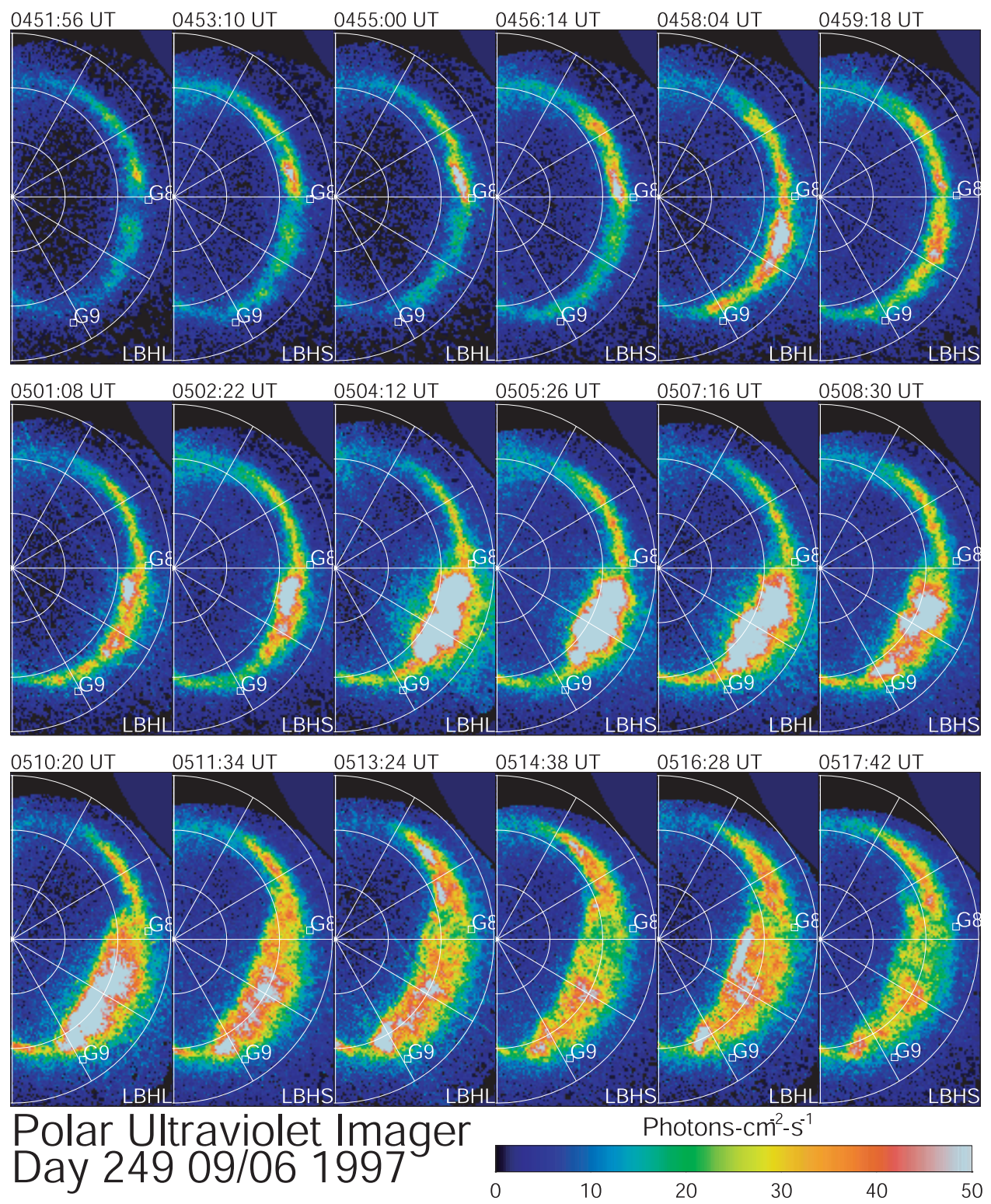

Figure 6. A sequence of nightside auroral images in the $\mathrm{N}_{2} \mathrm{LBH}$ bands from Polar ultraviolet imager showing auroral breakup at $\sim 0456: 42$ UT on 6 September 1997.

process of magnetic field lasts typically 1 hour and constitutes the substorm growth phase morphology at the nightside geosynchronous orbit [Kokubun and McPherron, 1981]. Since the present study is limited to moderate to large substorm events, a less stressed magnetic field may likely occur for small substorms. After onset the averaged field configuration recovered and returned at a faster speed to its presubstorm level in $\sim 10 \mathrm{~min}$. Overcompensation of the dipolarized magnetic field can occur after $\sim 10 \mathrm{~min}$ from the onset and may last over 1 hour. The duration of the field reconfiguration from a tail-like to a more dipole-like orientation signifies substorm expansion phase [Cumming et $a l ., 1968]$. Our study results indicate that this duration is $\sim 10$ min, which is in good agreement with the time required for auroral power reaching its maximum after onset [Newell et al., 2001]. Evolution of the magnetotail field configuration at the onset meridian at geosynchronous orbit during substorm periods has never been reported. This result certainly provides important information about typical magnetotail dynamic during substorm periods as a test bed for theories and models.

[26] On the basis of 32 dipolarization onsets observed within 2 hours in MLT from their associated auroral breakups, it is found that these dipolarization onsets at geosynchronous orbit often revealed delays with respective to the auroral breakups. The delay, as shown in Figure 8, was found to be associated not only with the azimuthal but also with earthward propagation/expansion of the dipolarization region. The average delay time is $1.7 \pm 2.7 \mathrm{~min}$. A smaller delay time of $1.0 \pm 2.1 \mathrm{~min}$ is obtained if the dipolarization events are limited to \pm 1 hour in MLT of the breakup (23 events in total in this category). 
[27] There is one question concerning the delay time of dipolarization in relation to the latitudinal separation. The minimum delay time took place when the GOES footprint was not at the same latitude as but $\sim 1^{\circ}$ poleward of the auroral breakup. Although, we cannot rule out the possibility of initiation of current disruption earthward of the geosynchronous orbit [Roux et al., 1991]. It is more likely that systematic errors in mapping the GOES satellite location using the T89 model could have yielded such a result. It is well known that the Earth's magnetic field is very stretched prior to substorm onset [Fairfield and Ness, 1970; Sauvaud and Winckler, 1980; Kokubun and McPherron, 1981; Nagai, 1982; Kaufmann, 1987; Lopez et al., 1998]. A stretched, tail-like field line can actually map a fixed point in the ionosphere to the equatorial magnetosphere farther down the tail than a dipole field model does. Conversely, a stretched, tail-like field line can map a fixed point in the magnetosphere to the ionosphere at a higher latitude than a dipole field model does. The three events that showed significant poleward of the auroral breakup in Figure 8 did correspond to low-latitude auroral onset $\left(63^{\circ}\right.$, $63.8^{\circ}$, and $64.9^{\circ}$, respectively), indicating that the magnetotail is very stretched and, consequently, making a reliable mapping impossible. This result may have put the possibility of a very close substorm initiation region significantly earthward of the geosynchronous orbit in doubt.

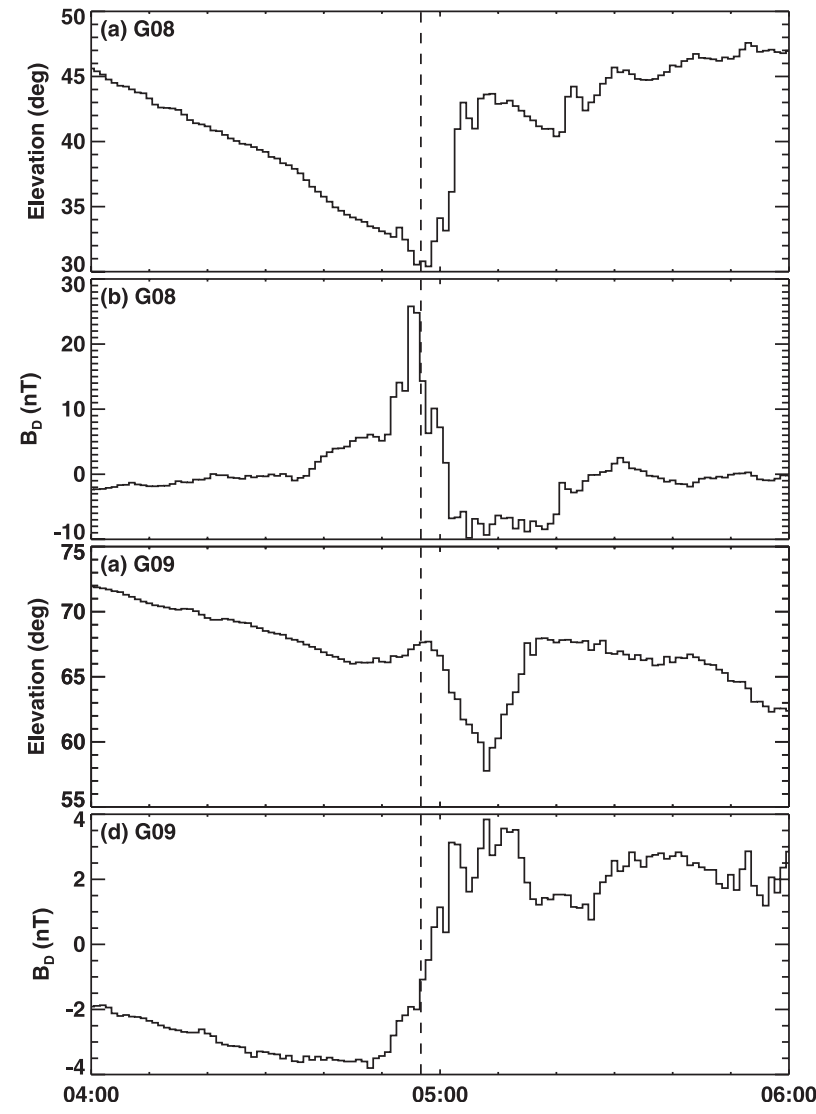

Figure 7. (a, c) The elevation angles and (b, d) $D$ component (east) of magnetic fields from GOES 8 and GOES 9, respectively, from 0400 to 0600 UT on 6 September 1997. The vertical dashed line marks the auroral onset time.

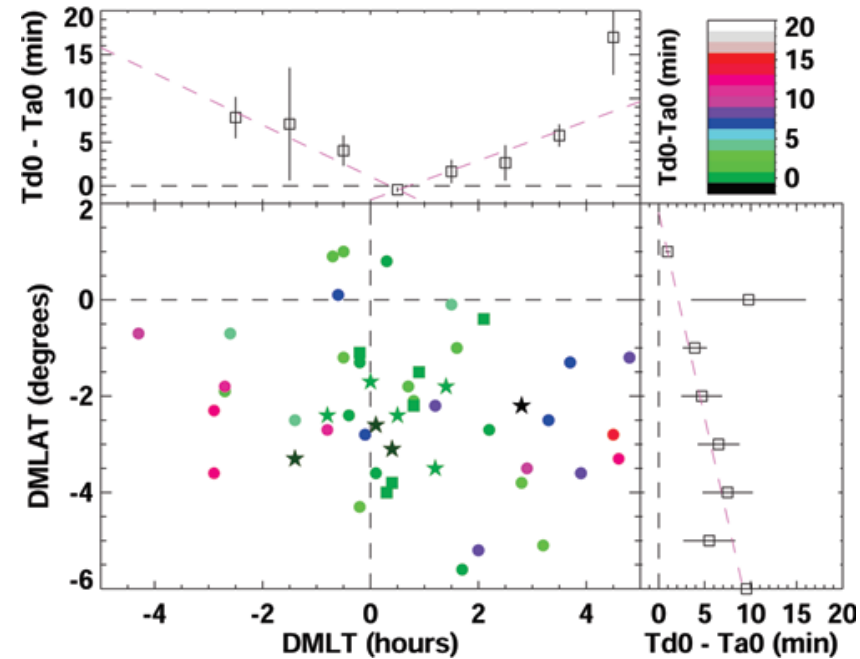

Figure 8. Time differences between the dipolarization onset $(T d 0)$ and auroral breakup (Ta 0$)$ as a function of (top) magnetic local time, (right) magnetic latitude, and (middle) both. In the middle panel the abscissa is the distance of the GOES ionospheric footprint from the auroral breakup in magnetic latitude $($ DMLAT $=$ MLAT(GOES) - MLAT (auroral breakup)), whereas the ordinate is the distance of the GOES ionospheric footprint from the auroral breakup in magnetic local time $($ DMLT $=$ MLT (GOES) - MLT $($ auroral breakup). Negative (postive) values of $T d 0-T a 0$ are represented by solid stars (solid circles) and zero values are denoted by solid squares.

[28] The two cases studied have unambiguously demonstrated that the delays of the dipolarization onsets with respect to the auroral breakups are due primarily to the azimuthal expansion of substorm auroral bulge. Although the delay time seems to be shorter when the dipolarization onset is closer to the breakup in general, the azimuthal expansion speed of auroral bulge, which is usually not constant or predictable, plays a more important role in the delay time. The azimuthal expansion of the substorm current wedge has been previously studied by many investigators with different means [Kokubun and McPherron, 1981; Nagai, 1982; Lopez et al., 1990]. These investigations have yielded a wide range of the expansion speed.

[29] Using six midlatitude ground magnetograms, Kokubun and McPherron [1981] found in one case a longitudinal speed of $\sim 2^{\circ} \min ^{-1}\left(\sim 24 \mathrm{~km} \mathrm{~s}^{-1}\right.$ at $\left.6.6 R_{E}\right)$ was responsible for the delays of peaks in the $H$ and $D$ components of magnetic field. By using GOES 2 and GOES 3 and groundbased magnetometer data, Nagai [1982] estimated that the dipolarized region expands $\sim 6.5^{\circ} \min ^{-1}\left(\sim 80 \mathrm{~km} \mathrm{~s}^{-1}\right.$ at $\left.6.6 R_{E}\right)$ duskward and $\sim 2.4^{\circ} \min ^{-1}\left(\sim 30 \mathrm{~km} \mathrm{~s}^{-1}\right.$ at $\left.6.6 R_{E}\right)$. Lopez et al. [1990] studied a substorm event with four specially configured satellites and estimated a propagation speed of $\sim 13^{\circ} \min ^{-1}\left(\sim 160 \mathrm{~km} \mathrm{~s}^{-1}\right.$ at $\left.6.6 R_{E}\right)$. The inferred expansion speeds of dipolarization region from the present study are $\sim 4.9^{\circ} \min ^{-1}\left(\sim 60 \mathrm{~km} \mathrm{~s}^{-1}\right.$ at $\left.6.6 R_{E}\right)$ westward and $\sim 6.1^{\circ} \min ^{-1}\left(\sim 75 \mathrm{~km} \mathrm{~s}^{-1}\right.$ at $\left.6.6 R_{E}\right)$ and are well within the speed range from previous studies and therefore represent typical speeds for the eastward and westward expansion of a current disruption region. The asymmetry 
of the eastward/westward expansion speed (faster westward and slower eastward) may be associated with the fact that expansion of a substorm bulge after onset is predominantly westward.

[30] Variation patterns in the $D$ component of the magnetic field at geosynchronous orbit during substorm periods may provide evidence of a pair field-aligned currents, one into the ionosphere from the east and one out of the ionosphere from the west of the substorm central meridian [Kokubun and McPherron, 1981]. The paired field-aligned currents are consequences of disruption and diversion of the east-to-west cross-tail current following the substorm onset [Atkinson, 1967; McPherron et al., 1973]. As shown in Figure 8 , the minimum delay time of dipolarization onset at geosynchronous orbit was offset 0.5 hour of local time eastward from the auroral breakup. Since the onset arcs are associated with an enhanced upward field-aligned current, a downward field-aligned current must be provided eastward of the onset region from the magnetosphere. Therefore the 0.5 hour of local time offset in the magnetosphere would correspond to a region where the cross-tail current is diverted as a field-aligned current into the ionosphere. According to Figure 4, the dipolarization arrived at GOES 8 at $\sim 0648$ UT when the magnetic footprint of GOES was located $\sim 0.5$ hour in MLT eastward of the eastward edge of the substorm bulge. Similar features are also observed in many other cases (not shown). Therefore the 0.5 hour local time offset corresponds to the eastward edge of the SCW. Since dipolarization expands both eastward and westward from a relatively narrow local time sector [Kokubun and McPherron, 1981; Nagai, 1982; Arnoldy and Moore, 1983; Lopez et al., 1998], the 0.5 hour offset of local time from the onset meridian would correspond to the dipolarization origin. Therefore the size of the initial dipolarization region should be $\sim 0.5$ hour of local time wide or slightly less than $1 R_{E}$ at $6.6 R_{E}$ and is in good agreement with case study results from Ohtani et al. [1991].

[31] It is generally accepted that magnetic field dipolarization [Cumming et al., 1968; McPherron et al., 1973; Sauvaud and Winckler, 1980; Kokubun and McPherron, 1981], presumably associated with diversion of the crosstail current into the ionosphere [Bonnevier and Rostoker, 1970; McPherron et al., 1973; Rostoker, 1974], and energetic particle injections (substorm injections) [Arnoldy and Chan, 1969; Mcllwain, 1974] are manifestations of magnetospheric substorms that initiate in the near-Earth magnetotail region. If the initiation is not local to the satellite, propagation delay in both onset signatures should be expected. Liou et al. [2001a] have recently analyzed 34 dispersionless (within $\sim 1$ min) substorm injection events by using high-energy electron and proton data from synchronous orbit particle analyzer (SOPA) on board the Los Alamos National Laboratory (LANL) 1994-084 and 1991080 spacecraft [see, e.g., Belian et al., 1992]. They found that dispersionless substorm injections at geosynchronous orbit often lagged behind their associated auroral breakup by an average of $1.8 \pm 2.5 \mathrm{~min}$. Since the dispersionless injections usually implies no magnetic gradient and curvature drift in the azimuthal directions, the delay of the dispersionless injections is due primarily to the earthward propagation/expansion of the onset region [Liou et al., 2001a], and this region is believed to be where cross-tail current disrupts. Particles can be energized by an induction electric field associated with the magnetic field dipolarization [Aggson et al., 1983].

[32] Previous observations have shown generally good correlation between dipolarization and particle injection [e.g., Sauvaud and Winckler, 1980; Lopez et al., 1989]. Detail comparison (within, say, 1-2 min) of onset timing of the two phenomena has surprisingly never been reported. Lack of reliable information about the substorm onset location for this type of study can lead to inconsistent results. The Polar UVI global auroral images not only provide unambiguously the onset location but the onset time. As clearly shown in Figure 8, the delay time of dipolarization depends strongly on the azimuthal location with respect to auroral breakup. The dipolarizations observed \pm 2 hours from the auroral breakups were subject to a large time delay due to the azimuthal expansion/ propagation of the source region. To compare the delay time of typical dipolarization onsets with typical dispersionless substorm injections, we need to restrict dipolarization events to match those set for the dispersionless events by Liou et al. [2001a]. According to their results, most (>91\%) of dispersionless (within $1 \mathrm{~min}$ ) energetic particle injection events were found \pm 1 hour of MLT from the auroral breakups. Under this condition the typical delay time for the dipolarization events ( 24 events) is found to be $1.1 \pm 2.4$ min, which is smaller than the typical delay time for dispersionless substorm injections observed at geosynchronous orbit. This surprising result seems to contradict the notion that a magnetic dipolarization is accompanied by an injection of energetic particles. Interestingly, the earthward propagation speed of dipolarization has been found in a range of $\sim 180-240 \mathrm{~km} \mathrm{~s}^{-1}$ [Russell and McPherron, 1973; Ohtani, 1998], which is about twice of the typical speed $\left(\sim 5-120 \mathrm{~km} \mathrm{~s}^{-1}\right)$ of substorm injections [Moore et al., 1981; Reeves et al., 1996; Liou et al., 2001a]. If both dispersionless substorm injections and magnetic dipolarization are produced at the time and the location of the substorm onset and subsequently expand/propagate earthward, different timing should be expected earthward of the onset initiation site such as the geosynchronous orbit. Our statistical results, though obtained separately from different studies with different substorm events, support this view.

[33] It has been suggested that the frozen-in condition predicted by the MHD theory cannot be used in the turbulent, substorm initiation regions [Lui, 1996]. As a result, magnetic field and plasma do not move together. If it is true, then a similar delay time for magnetic dipolarizations and for dispersionless substorm injections should not be expected because substorms are generally initiated just outside of the geosynchronous orbit. Recently, Lui et al. [1999] studied a substorm event when Geotail was in the plasma sheet at $X_{G S M} \sim-10 R_{E}$. They found that the dipolarization associated with the substorm occurred without significant plasma flow or with tailward flow and during dawnward electric field. These observations clearly indicate that dipolarization is a non-MHD process. Therefore great caution must be taken when interpreting modeled substorm results that based on the MHD theory. On the other hand, a typical longer time for a dispersionless substorm injection than for a magnetic dipolarization to be seen at geosynchronous orbit may simply indicate that the injection is 
produced at a slightly later time than the dipolarization, perhaps associated with particle energization processes/ mechanisms. Further work is necessary to address this possibility.

[34] Comparison of onset timing between auroral breakup and dipolarization has been previously conducted by Frank et al. [2000] by using global auroral images and in situ measurements of magnetic field in the midtail region. They found an event of simultaneous dipolarization onset and auroral breakup in the two events studied. This particular event was observed by Geotail at a geocentric radial distance of $\sim 14 R_{E}$ and within tens of minutes in local time of the magnetic field lines threading the onset auroral arcs. If dipolarization of magnetic field is associated with cross-tail current disruption, which occurs preferentially in the near-Earth plasma sheet from 6 to $10 R_{E}$ [Lui, 1991; Kennel, 1992], the actual dipolarization time should be earlier. It has been reported that the region of current disruption associated with substorms expands tailward at a speed of 2-300 $\mathrm{km} \mathrm{s}^{-1}$ [Jacquey et al., 1991; Jacquey et al., 1993; Ohtani et al., 1992; Baumjohann et al., 1999]. Since the onset arc for their simultaneous event was mapped to a geocentric radial distance of $\sim 10 R_{E}$ [Frank et al., 2000], it would take at least $\sim 1$ min for the dipolarization signature to arrive at Geotail. Therefore the dipolarization event they studied might have occurred at least $\sim 1 \mathrm{~min}$ prior to the brightening of onset arcs. Our statistical results indicate that when GOES satellites were favorably located, the dipolarization at geosynchronous orbit may precede the auroral breakup by $\sim 1 \mathrm{~min}$. The actual dipolarization time may have been even earlier if the propagation effect is taken into account. Therefore we conclude that dipolarization must occur at least $\sim 1$ min prior to auroral breakup. This delay time must correspond to a round trip time for Alfvén waves communicating electromagnetic energy between the magnetosphere and the ionosphere, which is of the order of $1 \mathrm{~min}$ at $10 R_{E}$. Therefore auroral breakup can be used to time magnetospheric substorm onset with a small time delay of $\sim 1 \mathrm{~min}$ associated with the Alfvén transit time.

[35] Temporal relationships among substorm onset signatures are a building block for substorm models. The present finding of the time sequence between auroral breakups and magnetic dipolarizations confirms that both substorm onset signatures originate from a same source in the near-Earth plasma sheet. There has been a number of observational evidence indicating that substorm expansive phase onset starts in the near-Earth plasma sheet $\left(4-10 R_{E}\right)$ [e.g., Lopez et al., 1990; Samson et al., 1992; Jacquey et al., 1991; Lui, 1991; Erickson et al., 2000; Frank et al., 2000]. A slightly different approach based on time-of-flight analysis used by Liou et al. [2001a] and the present paper also suggests that the onset is first initiated in the near-Earth plasma sheet from $X \sim-7$ to $X \sim-10 R_{E}$. Using Geotail magnetic field observations, Lui et al. [1998] produced a temporal sequence of magnetic field changes in the $B_{z}$ component relative to the averaged value \pm 10 from auroral breakups. They found that dipolarization first appeared at $X \sim=-10 R_{E}$ (the closest orbit to Earth in the midnight sector) near midnight $2 \mathrm{~min}$ (or 1-3 min) after the auroral breakups. This 2-min delay is most likely due to an expansion of the dipolarization region from a source inside of $10 R_{E}$ from Earth. This mounting evidence, along with the present result, strongly suggests that dipolarizations take place typically inside of $X \sim-10 R_{E}$.

[36] Once the relationships between dipolarizations and auroral breakups are established, we should be able to test substorm models. There are two major competing substorm models: the near-Earth neutral line (NENL) model [e.g., Baker et al., 1996 and references therein] and the current disruption (CD) model [e.g., Lui, 1996 and references therein]. While most proponents of the two models accept the idea about the formation of substorm current wedge and near-Earth neutral line near substorm onset, the major wrangle between the two sides is which causes which. The advocates of the NENL model insist that it is the reconnection in the midtail region that initiates a sequence of substorm process, including the formation of a substorm current wedge in the inner plasma sheet region, while the supporters of the $\mathrm{CD}$ model believe that the substorm expansive phase is initiated in the near-Earth plasma sheet prior to the midtail reconnection. Therefore, to test these two models, one needs to compare the temporal sequence of a number of near onset substorm features.

[37] According to the NENL model, reconnection must occur prior to substorm onset. The major signatures predicted by reconnection are fast earthward plasma flows and tailward moving plasmoids. Lui et al. [1998] have recently studied synoptic patterns of plasma and magnetic field at Geotail orbits $\left(-X \sim 10-30 R_{E}\right.$ and $\left.|\mathrm{Y}| \leq 20 R_{E}\right)$ near auroral onset. They found that dipolarization and fast tailward flows occurred at $X \sim=-10 R_{E}$ and $X \sim=-28$ $R_{E}$, respectively, $2( \pm 1)$ min after the auroral onset. More recently, Miyashita et al. [2000] conducted a similar study for the plasma flow and magnetic field patterns using the Geotail data but with respective to Pi2 onset. They concluded that fast tailward flows, associated with plasmoids, started to develop in the premidnight plasma sheet $(X \sim=$ $\left.-28 R_{E}\right) 1( \pm 1)$ min before Pi2 onset and increases in $B_{z}$ (dipolarization) started immediately after the $\mathrm{Pi} 2$ onset. Although there is a 2-3 min difference between the two study results, they are reasonably consistent because Pi2 onset lags behind auroral onset by 1-3 $\mathrm{min}$ [Liou et al., 2000a].

[38] From these timing studies, one can estimate the time for reconnection to occur relative to magnetospheric substorm onset (dipolarization). Previous studies have shown evidence indicating that the near-Earth neutral line is located between $X \sim-19 R_{E}$ and $X \sim-30 R_{E}$ [Nagai et al., 1998, Baumjohann et al., 1999]. With a significantly larger number of Geotail events, Miyashita et al. [2000] determined the typical neutral line to be $X \sim-20 R_{E}$. We will take the neutral line location at this location $(X \sim-20$ $R_{E}$ ) and $400 \mathrm{~km} \mathrm{~s}^{-1}$ for the speed of plasmoids (taken from both Lui et al. [1998] and Miyashita et al. [2000] results), it will take $2 \mathrm{~min}$ for the plasmoids to propagate and to be seen at $X \sim-28 R_{E}$. Therefore reconnection must be created 2 min prior to the dipolarization onset $(1 \mathrm{~min}$ prior to the auroral onset). According to the NENL model, substorm current disruption is caused by braking of earthward fast flows Shiokawa et al. [1998]. Therefore the model requires that a fast flow propagate from $X \sim-20 R_{E}$ to $X \sim$ $-8 R_{E}$ in $0-1 \mathrm{~min}$, implying an unrealistic fast flow speed of at least $\sim 1300 \mathrm{~km} \mathrm{~s}^{-1}$. An average time of $4 \mathrm{~min}$ is 
required for a typical fast flow speed of $300 \mathrm{~km} \mathrm{~s}^{-1}$. This implies that NENL signatures should be seen at $X \sim-28 R_{E}$ 3 min prior to auroral breakup, which obviously contradicts the Geotail observations. These self-inconsistencies suggest that near-Earth reconnection cannot occur before current disruption.

[39] On the other hand, these results seem to support the CD model. If a substorm is initiated at $X \sim 8 R_{E}$ in the nightside tail region, it will take $1-2 \mathrm{~min}$ for the dipolarization region reaches $X \sim-10 R_{E}$, as shown in both Lui et al. [1998] and Miyashita et al. [2000] results. According to the CD model, it is a rarefaction wave originating from the current disruption that causes further thinning of the midtail plasma sheet, ultimately leading to reconnection in the midtail region. Since typical fast-mode waves in the midtail region have a speed of a few thousand $\mathrm{km} \mathrm{s}^{-1}$ Moore et al. [1987], it only takes $\sim 1$ min or less of the traveling time to reach the typical reconnection site $\left(X \sim-20 R_{E}\right)$, thereby a tailward moving plasmoid is produced and can be observed 2 min later at $X \sim-28 R_{E}$, as shown in both Lui et al. [1998] and Miyashita et al. [2000] results. Another strong support for the CD model is that fast earthward flows were rarely observed before substorm onset [Lui et al., 1998; Miyashita et al., 2000]. Naturally, we cannot role out any other model that satisfies the above observational constraints.

\section{Summary and Conclusions}

[40] We have investigated the characteristics of dipolarization at geosynchronous altitude in terms of relative timing and location relative to auroral breakup. On the basis of 32 events that occurred within 2 hours in MLT from the auroral breakup, as determined from T89 magnetic field model, we found the following:

1. The onset of magnetic field dipolarization can have a delay of as much as 9 min relative to the auroral onset, though the average delay was much smaller, $\sim 1.7 \pm 2.7 \mathrm{~min}$ $(\sim 1.0 \pm 2.1 \mathrm{~min}$ for GOES being located \pm 1 hour from the breakup). A larger delay of more than $10 \mathrm{~min}$ is also possible for satellites located further away in local time from the breakup.

2. The delay time represents a propagation time in association with the expansion of auroral bulge in both latitudinal and longitudinal directions.

3. Dipolarization can be observed $\sim 1$ min prior to auroral breakup when GOES was located $\sim 0.5$ hour in MLT eastward of the breakup meridian, indicating that dipolarization, at its onset site, must occur at least $1 \mathrm{~min}$ prior to auroral breakup, depending on the Alfvén transit time.

4. The typical expansion speed of the current disruption region was estimated to be $60 \mathrm{~km} \mathrm{~s}^{-1}$ westward and $75 \mathrm{~km} \mathrm{~s}^{-1}$ eastward at $6.6 R_{E}$.

5. The average radial distance of initiation site was estimated to be $8.3 R_{E}$, and the azimuthal scale of the initial dipolarization region is $\sim 1 R_{E}$ at this location.

[41] We also showed for the first time that dipolarization and auroral bulge closely map. The bulge is the region of currents out of the ionosphere. These results support current diversion into the ionosphere a a critical part of substorms. Timing analysis of the temporal sequence of near-substorm onset signatures favors the notion that the near-Earth neutral line in the midtail region is not a cause of current disruption in the near-tail plasma sheet.

[42] Acknowledgments. We acknowledge G. Parks as the principal investigator for the ultraviolet imager on board the Polar satellite. This work was supported in part by NASA grants NAG 5-9078 and NAG 5-11350 and in part by AFOSR through the NSF grant ATM0001665 to the Johns Hopkins University Applied Physics Laboratory.

[43] Janet G. Luhmann thanks Christian Jacquey and another referee for their assistance in evaluating this paper.

\section{References}

Aggson, T. L., J. P. Heppner, and N. C. Maynard, Observations of large magnetospheric electric fields during the onset phase of a substorm, $J$. Geophys. Res., 88, 3981, 1983.

Akasofu, S.-I., The development of the auroral substorm, Planet. Space Sci., 12, 273, 1964.

Arnoldy, R. R., and K. W. Chan, Particle substorms observed at the geostationary orbit, J. Geophys. Res., 74, 5019, 1969.

Arnoldy, R. L., and T. E. Moore, The longitudinal structure of substorm injections at synchronous orbit, J. Geophys. Res., 88, 6213, 1983.

Atkinson, G., An approximate flow equation for geomagnetic flux tubes and its application to polar substorms, J. Geophys. Res., 72, 5373, 1967.

Baker, D. N., T. I. Pulkkinen, V. Angelopoulos, W. Baumjohann, and R. L. Baumjohann, Neutral line model of substorms: Past results and present view, J. Geophys. Res., 101, 12,975, 1996.

Baker, K. B., and S. Wing, A new coordinate system for conjugate studies at high latitudes, J. Geophys. Res., 94, 9139, 1989.

Baumjohann, W., M. Hesse, S. Kokubun, T. Mukai, T. Nagai, and A. A. Petrukovich, Substorm dipolarization and recovery, J. Geophys. Res., 104, 24,995, 1999.

Belian, R. D., G. R. Gisler, T. E. Cayton, and R. A. Christensen, High-Z energetic particles at geosynchronous orbits during the great solar proton event series of October, 1989, J. Geophys. Res., 97, 16,897, 1992.

Bonnevier, B. R., and G. Rostoker, A three-dimensional model current system for polar magnetic substorms, J. Geophys. Res., 75, 107, 1970.

Cumming, W. D., J. N. Barfield, and P. J. Coleman, Magnetospheric substorms observed at synchronous orbit, J. Geophys. Res., 73, 6687, 1968.

Erickson, G. M., N. C. Maynard, W. J. Burke, G. R. Wilson, and M. A. Heinemann, Electromagnetics of substorm onsets in the near-geosynchronous plasma sheet, J. Geophys. Res., 105, 25,265, 2000.

Fairfield, D. H., and N. F. Ness, Configuration of the geomagnetic tail during substorms, J. Geophys. Res., 75, 7032, 1970.

Frank, L. A., W. R. Paterson, J. B. Sigwarth, and S. Kokubun, Observations of magnetic field dipolarization during auroral substorm onset, J. Geophys. Res., 105, 15,897, 2000.

Gelpi, C., H. J. Singer, and W. J. Hughes, A comparison of magnetic signatures and DMSP auroral images at substorm onset: Three case studies, J. Geophys. Res., 92, 2447, 1987.

Jacquey, C. J., A. Sauvaud, and J. Dandouras, Location and propagation of the magnetotail current disruption during substorm expansion: Analysis and simultation of an ISEE multi-onset event, Geophys. Res. Lett., 18, 389,1991

Jacquey, C. J., A. Sauvaud, J. Dandouras, and A. Korth, Tailward propagating cross-tail current disruption and dynamics of near-Earth tail: Multipoint measurement analysis, Geophys. Res. Lett., 20, 983, 1993.

Kaufmann, R. L., Substorm currents: Growth phase and onset, J. Geophys. Res., 92, 7471, 1987.

Kennel, C., The Kiruna conjecture: The strong version, in Proceedings of the International Conference on Substorms (ICS-1), Eur. Space Agency Spec. Publ., ESA SP-335, 599, 1992.

Kokubun, S., and R. L. McPherron, Substorm signatures at synchronous altitude, J. Geophys. Res., 86, 11,265, 1981.

Liou, K., C.-I. Meng, A. T. Y. Lui, P. T. Newell, M. Brittnacher, G. Parks, G. D. Reeves, R. R. Anderson, and K. Yumoto, On relative timing in substorm onset signatures, J. Geophys. Res., 104, 22,807, 1999.

Liou, K., C.-I. Meng, A. T. Y. Lui, P. T. Newell, and R. R. Anderson, Auroral kilometric radiation (AKR) at substorm onset, J. Geophys. Res., 105, 25,325, 2000a.

Liou, K., C.-I. Meng, P. T. Newell, K. Takahashi, S.-I. Ohtani, A. T. Y. Lui, M. Brittnacher, and G. Parks, Evaluation of low-latitude Pi2 pulsations as indicators of substorm onset using Polar ultraviolet imagery, J. Geophys. Res., 105, 2495, 2000b.

Liou, K., C.-I. Meng, P. T. Newell, A. T. Y. Lui, G. Reeves, and R. Belian, Particle injections with auroral expansions, J. Geophys. Res., 106, 5873, 2001a. 
Liou, K., P. T. Newell, D. G. Sibeck, C.-I. Meng, M. Brittnacher, and G. Parks, Observation of IMF and seasonal effects in the location of auroral substorm onset, J. Geophys. Res., 106, 5799, 2001b.

Lopez, R. E., A. T. Y. Lui, D. G. Sibeck, K. Takahashi, and R. W. McEntire, On the relationship between the energetic particle flux morphology and the change in the magnetic field magnitude during substorms, J. Geophys. Res., 94, 17,105, 1989.

Lopez, R. E., D. G. Sibeck, R. W. McEntire, and S. M. Krimigis, The energetic ion substorm injection boundary, J. Geophys. Res., 95, 109, 1990.

Lopez, R. E., D. G. Sibeck, A. T. Y. Lui, K. Takahashi, R. W. McEntire, T. A. Potemra, and D. Klumper, Substorm variations in the magnitude of the magnetic field, J. Geophys. Res., 103, 14,444, 1998.

Lui, A. T. Y., A synthesis of magnetospheric substorm models, J. Geophys. Res., 96, 1849, 1991

Lui, A. T. Y., Current disruption in the Earth's magnetopshere: Observations and models, J. Geophys. Res., 101, 13,067, 1996.

Lui, A. T. Y., K. Liou, P. T. Newell, C.-I. Meng, S.-I. Ohtani, T. Ogino, S Kokubun, M. J. Brittnacher, and G. K. Parks, Plasma and magnetic flux transport associated with auroral breakups, Geophys. Res. Lett., 25, 4059, 1998.

Lui, A. T. Y., K. Liou, M. Nosé, S. Ohtani, D. J. Williams, T. Mukai, K Tsuruda, and S. Kokubun, Near-Earth dipolarization: Evidence for a nonMHD process, Geophys. Res. Lett., 26, 2905, 1999.

McIlwain, C. E., Substorm injection boundaries, in Magnetospheric Physics, edited by B. M. McCormac, p. 143, D. Reidel, Norwell, Mass. 1974.

McPherron, R. L., C. T. Russell, and M. P. Aubry, Satellite studies of magnetospheric substorms on August 15, 1968, 9, Phenomenological model for substorms, J. Geophys. Res., 78, 3131, 1973.

Miyashita, Y., S. Machida, T. Mukai, Y. Saito, K. Tsuruda, H. Hayakawa, and P. R. Sutcliffe, A statistical study of variations in the near and middistant magnetotail associated with substorm onsets: Geotail observations, J. Geophys. Res., 105, 15,913, 2000.

Moore, T. E., R. L. Arnoldy, J. Feynman, and D. A. Hardy, Propagating substorm injection fronts, J. Geophys. Res., 86, 6713, 1981.

Moore, T. E., D. L. Gallagher, J. L. Horwitz, and R. H. Comfort, MHD wave breaking in the outer plasmasphere, Geophys. Res. Lett., 14, 1007 , 1987.

Nagai, T., Observed magnetic substorm signatures at synchronous altitude, J. Geophys. Res., 87, 4405, 1982

Nagai, T., et al., Structure and dynamics of magnetic reconnection for substorm onsets with Geotail observations, J. Geophys. Res., 103 4419, 1998
Newell, P. T., K. Liou, T. Sotirelis, and C.-I. Meng, Polar ultraviolet imager observations of global auroral power as a function of polar cap size and magnetotail stretching, J. Geophys. Res., 106, 5895, 2001.

Ohtani, S., Earthward expansion of tail current disruption: Dual-satellite study, J. Geophys. Res., 103, 6815, 1998.

Ohtani, S., K. Takahashi, L. J. Zanetti, T. A. Potemra, R. W. McEntire, and T. Iijima, Tail current disruption in the geosynchronous region, in Magnetospheric Substorms, Geophys. Monogr. Ser, vol. 64, edited by J. Kan et al., p. 131, AGU, Washington, D. C., 1991.

Ohtani, S., S. Kokubun, and C. T. Russell, Radial expansion of the tail current disruption during substorms: A new approach to the substorm onset region, J. Geophys. Res., 97, 3129, 1992.

Pellinen, R., A. Huuskonen, and M. Vallinkoski, GOES 2 E-field behavior during dynamic auroral development near the satellite footprint, Eur. Space Agency Spec. Publ., ESA, SP-217, 358, 1984.

Reeves, G. D., R. W. H. Friedel, M. G. Henderson, A. K. McLachlan, P. S. McLachlan, and R. D. Belian, Radial propagation of substorm injections, in Substorms 3, Eur. Space Agency Spec. Publ., ESA SP-389, 579, 1996.

Rostoker, G., Current flow in the magnetosphere during magnetospheric substorms, J. Geophys. Res., 79, 1994, 1974.

Roux, A., S. Perraut, P. Robert, A. Morane, A. Pedersen, A. Korth, G. Kremser, B. Aparicio, D. Rodgers, and R. Pellinen, Plasma sheet instability related to the westward traveling surge, J. Geophys. Res., 96, 17,697, 1991.

Russell, C. T., and R. L. McPherron, The magnetotail and substorms, Space Sci. Rev., 15, 205, 1973.

Samson, J. C., L. R. Lyons, P. T. Newell, F. Creutzberg, and B. Xu, Proton aurora and substorm intensifications, Geophys. Res. Lett., 19, 2167, 1992.

Sauvaud, J.-A., and J. R. Winckler, Dynamics of plasma, energetic particles, and fields near synchronous orbit in the nighttime sector during magnetospheric substorms, J. Geophys. Res., 85, 2043, 1980.

Shiokawa, K., et al., High-speed ion flow, substorm current wedge, and multiple Pi2 pulsations, J. Geophys. Res., 103, 4491, 1998.

Torr, M. R., et al., A far ultraviolet imager for the international solarterrestrial physics mission, Space Sci. Rev., 71, 329, 1995.

Tsyganenko, N. A., A solution of the Chapman-Ferraro problem for an ellipsoidal magnetopause, Space Sci. Rev., 71, 329, 1989.

K. Liou, A. T. Y. Lui, C.-I. Meng, P. T. Newell, and S. Wing, Johns Hopkins University, Applied Physics Laboratory, Laurel, MD 20723, USA. (kan.liou@jhuapl.edu; tony.lui@jhuapl.edu; ching.meng@jhuapl.edu; patrick.newell@jhuapl.edu; simon.wing@jhuapl.edu) 